\title{
Prevalence and Determinants of Glucose Abnormalities among Patients with Chronic Liver Disease in Alexandria, Egypt
}

\author{
Iman Wahdan $^{1 ¥}$, Marwa Madkour², Nessrin El-Nimr ${ }^{1}$ \\ ${ }^{1}$ Department of Epidemiology, High Institute of Public Health, Alexandria University, Egypt \\ ${ }^{2}$ Department of Clinical and Experimental Internal Medicine, Medical Research Institute, Alexandria University, Egypt
}

\begin{abstract}
Background: The term Chronic liver disease (CLD) encompasses a large number of conditions existing on a continuum between hepatitis infection and cirrhosis. Chronic hepatitis $\mathrm{C}$ infection was found to be associated with diabetes mellitus (DM) with a significantly higher prevalence than the prevalence in the general population.

Objectives: The aim of the present study was to assess the prevalence and determinants of glucose abnormalities among patients with CLD in Alexandria, Egypt.

Methods: Over a period of two years, 264 consecutive patients with CLD referred to the Hepatology and Gastroenterology Unit, Medical Research Institute, Alexandria University were enrolled in the study. Personal, demographic and medical histories were obtained by interviewing each patient and reviewing his/her records. Clinical examination for each patient was also performed. Complete blood picture, fasting blood glucose level and lipid profile, liver profile and imaging were recorded. Serological and/or immunological markers identifying the etiology of CLD were also recorded.

Results: The prevalence of glucose abnormalities among hepatitis $\mathrm{C}$ positive patients was higher than that among patients with other CLD (39.2\% versus $21.7 \%$ respectively), with a statistically significant difference. Three independent risk factors were found to be significantly affecting the prevalence of glucose abnormalities among CLD patients; namely etiology of liver disease, presence of fatty liver and total cholesterol level.

Conclusion: The present study indicates a high prevalence of DM in patients with CLD in Alexandria. It is therefore imperative that patients with CLD especially chronic hepatitis C patients be screened periodically for glucose intolerance.
\end{abstract}

Keywords: Chronic liver disease, diabetes mellitus, impaired fasting glucose, hepatitis C

Available on line at: www.ebscohost.com

$¥$ Correspondence:

Email: imanwahdan@yahoo.com Tel: 00201000022252

Suggested Citation: Wahdan I Madkour M, El-Nimr N. Prevalence and Determinants of Glucose Abnormalities among Patients with Chronic Liver Disease in Alexandria, Egypt. Bull. HIPH. 2014;44(1):1-7.

\section{INTRODUCTION}

$\mathrm{C}$ hronic liver disease (CLD) is a condition marked by the gradual destruction of liver tissue over time..$^{(1)}$ The term CLD encompasses a large number of conditions having different etiologies and existing on a continuum between hepatitis infection and cirrhosis. ${ }^{(2)}$ In Egypt, there is a high morbidity and mortality from CLD. ${ }^{(3)}$ Hepatitis $\mathrm{C}$ virus (HCV) infection is considered the most common etiology of CLD in Egypt. ${ }^{(4)}$ Clinical studies showed that 70-90\% of Egyptian patients with CLD had HCV infection. ${ }^{(3)}$ Chronic HCV infection was found to be associated with diabetes mellitus (DM). This association was first reported by Alison et al in 1994. ${ }^{(5)}$ In the mid-1990s, researchers began to report a high prevalence of DM in people with chronic HCV infection. ${ }^{(6,}$ ${ }^{7)}$ Case control studies revealed that the proportion of DM in patients with chronic HCV infection ranged between $21 \%$ and $50 \%$. This prevalence was significantly higher than the prevalence in the general population (2-4 times more common). ${ }^{(8)}$ The contribution of HCV infection to DM could be explained by the fact that HCV may infect and damage the insulin producing beta cells of the pancreas. Also, HCV is known to be associated with some autoimmune phenomena, where the immune system of patients with HCV may attack the insulin producing cells. ${ }^{(9)}$ Furthermore, liver inflammation or damage due to HCV may affect the production of glucose or the metabolism of insulin by the liver thus altering the blood sugar levels. In fact, cirrhosis of the liver was proved by itself - regardless of etiology - to increase the risk of insulin resistance. In this context, the term "hepatogenous diabetes" (which is diabetes developing as a complication of cirrhosis) was described. Insulin resistance in muscular, hepatic and 
adipose tissues as well as hyperinsulinemia, seemed to be the main pathophysiologic bases for hepatogenous diabetes. $^{(10)}$

The current study was conducted to assess the prevalence and determinants of glucose abnormalities among patients with CLD in Alexandria, Egypt.

\section{METHODS}

For a duration of two years, from March 2012 till the end of January 2014, all consecutive patients with chronic liver disease (CLD) referred to the Hepatology and Gastroenterology Unit (HGU) of Internal Medicine Department, Medical Research Institute (MRI) in Alexandria (Egypt), were enrolled in the study. The HGU of MRI is one of two specialized CLD referral centers of Alexandria University, serving patients from Alexandria and El-Beheira Governorates. Patients below 20 years of age, pregnant females, patients under regular corticosteroid therapy, patients with pancreatic diseases (tumors or pancreatitis), as well as patients with hepatocellular carcinoma (screened by serum alpha-fetoprotein level and abdominal ultrasonography) and patients with history of type 1 (autoimmune) diabetes were excluded from the study. A total number of 264 CLD patients were included in the study.

Personal, demographic and medical histories were obtained by interviewing each patient and reviewing his/her records. Clinical evaluation of CLD signs was performed, and patient's weight and height were assessed. Laboratory data including complete blood picture [hemoglobin level, white blood cell (WBC) and platelets count], lipid profile (total cholesterol and triglycerides), fasting blood glucose level and liver profile [Gamma-glutamyl transferase (GGT), alanine aminotransferase (ALT), aspartate aminotransferase (AST), serum albumin, serum bilirubin, prothrombin time and activity] were recorded. For each parameter, normal and abnormal values were indicated. ${ }^{(11)}$ The presence or absence of liver cirrhosis, fatty liver changes (steatosis), periportal fibrosis and ascites (by ultrasound evaluation) was also noted. Moreover, the Child-Pugh score was calculated for each cirrhotic patient. ${ }^{(12)}$

Chronic liver disease patients entailed two main categories; liver cirrhosis and chronic hepatitis. Diagnosis of cirrhosis was confirmed by clinical signs or biochemical evidence of liver decompensation, in addition to ultrasound features of cirrhosis, fibrosis and portal hypertension. Chronic hepatitis implied persistent inflammation of the liver for six months or more after initial exposure and/or initial detection of liver disease. All chronic hepatitis patients had records of elevated serum aminotransferases for more than six months, liver biopsy evidence of chronic inflammation, in addition to serological and/or immunological markers identifying the etiology of CLD; e.g. viral hepatitis molecular assays by qualitative Real Time-Polymerase Chain Reaction (RT-PCR), serum markers of autoimmune, metabolic and schistosomal liver disease, as well as sonographic and echocardiography evidence of cardiac cirrhosis and Budd Chiari syndrome. ${ }^{(12)}$

Diabetes was defined on the basis of a history of therapy with oral hypoglycemic agents or insulin at the time of inclusion. In patients who were not previously known to be diabetic, diabetes was diagnosed if the fasting blood glucose was $\geq 126 \mathrm{mg} / \mathrm{dl}$ on two separate occasions and impaired fasting glucose (IFG) if the fasting blood glucose was between $101 \mathrm{mg} / \mathrm{dl}$ and $\leq 125 \mathrm{mg} / \mathrm{dl}^{(11)}$

Hypertension was defined by either a history of therapy with antihypertensive agents at the time of inclusion; or blood pressure measurement equal to or greater than 140/90 $\mathrm{mmHg}$ on two or more occasions. ${ }^{(13)}$ Patients with hemoglobin concentration less than $13 \mathrm{~g} / \mathrm{dl}$ (for males) and less than $12 \mathrm{~g} / \mathrm{dl}$ (for females) were considered "anemic". (11)

Body mass index (BMI) was calculated using the standard formula (BMI=weight in $\mathrm{kg} /$ height in $\mathrm{m}^{2}$ ). BMI was not calculated for patients with clinical or sonographic evidence of ascites and/or lower limb edema. ${ }^{(14)}$

\section{Data management and statistical analysis}

The collected data were coded and entered using SPSS for Windows version 16.0 (SPSS Inc., Chicago, IL, USA). Descriptive statistics using frequency distribution tables and graphs were done. For quantitative variables, mean and standard deviation were calculated. Percent and Pearson's Chi Square were used for analysis of categorical data. Whenever Chi Square was not valid, Fisher Exact Test (FET) was used for 2x2 tables and Monte Carlo probability test (MCP) for $\mathrm{RxC}$ tables. Multiple logistic regression analysis was used to estimate the strength of association between the exposure and a binary outcome (presence of glucose abnormalities). All statistical analyses were done using two tailed tests and a $p$ value of less than 0.05 was considered to be statistically significant.

\section{Ethical Statement}

The study was approved by the Ethics Committee of the High Institute of Public Health, Alexandria University. An informed consent was obtained from each patient who agreed to participate in the study after explanation of the purpose of research. Confidentiality and anonymity were guaranteed and maintained.

\section{RESULTS}

The mean age of the studied patients was $54.2 \pm 10.18$ years. Age ranged between 29 and 89 years. Males represented $61 \%$ of the sample. The mean BMI (calculated only for patients with no ascites or lower limb edema) was $28.24 \pm 3.10$. It ranged between 22.91 and $36.44 \mathrm{~kg} / \mathrm{m}^{2}$. About two thirds of the participants $(61.5 \%)$ were overweight, $34.1 \%$ were hypertensives, $38.3 \%$ had a family history of diabetes and $45.5 \%$ were smokers. Almost all participants $(97.7 \%)$ were anemic, $46.2 \%$ had low WBC count, while $86.4 \%$ had low platelets count. As regards the lipid profile, $35.2 \%$ and $17.8 \%$ had borderline and high triglycerides levels, respectively, while $25 \%$ and $10.2 \%$ had borderline and high total cholesterol levels, respectively. Nearly one third of the participants $(33.7 \%)$ had abnormal 
blood glucose levels (10.6\% had IFG and $23.1 \%$ were diabetics).

About two thirds $(68.6 \%)$ of the patients were HCV positive, while $31.4 \%$ had other CLD including

schistosomal hepatic fibrosis $(8.7 \%)$, primary biliary cirrhosis $(7.6 \%)$, cardiac cirrhosis $(4.2 \%)$, hepatitis B (3\%), cryptogenic cirrhosis (2.3\%), hemochromatosis, Budd Chiari syndrome, primary sclerosing cholangitis and alcoholic liver cirrhosis (1.1\% each). Glycogen storage disease and Wilson's disease represented $1.2 \%$ of patients. Regarding liver functions, $92.4 \%$ had low serum albumin levels, $81.1 \%$ had prolonged prothrombin time, $88.3 \%$ had diminished prothrombin activity and $81.4 \%$ had elevated serum bilirubin. Nearly half of the patients had elevated GGT and ALT levels (44.3\% and 49.2\% respectively), while $85.6 \%$ had elevated AST levels. About two thirds of patients had fatty liver (61\%), while almost all participants (95.1\%) had liver cirrhosis/fibrosis. Among cirrhotic patients, $70.5 \%$ were Child class $\mathrm{C}$.

Table 1 shows that the highest proportion of CLD patients with glucose abnormalities were 60 to less than 70 years of age. The association between age and glucose abnormalities among CLD patients was not statistically significant. Almost equal percentages of males and females with CLD had glucose abnormalities with a statistically insignificant difference. It is clear from the table that the proportion of CLD patients with glucose abnormalities increased with the increase in the BMI. This difference was statistically significant $\left(\mathrm{X}^{2}=14.99, \mathrm{p}=0.001\right)$.

More than half of CLD patients who were hypertensive or had a family history of diabetes had glucose abnormalities. These differences were statistically significant $\left(\mathrm{X}^{2}=32.197, \mathrm{X}^{2}=28.56, \mathrm{p}=0.000\right.$ respectively). Among CLD patients, almost equal proportions of smokers and non-smokers had fasting blood glucose abnormalities, with no statistically significant difference. Higher percentages of abnormal fasting blood glucose levels were noticed among CLD patients who received interferon treatment compared to those who did not $(40.4 \%$ and $32.9 \%$, respectively). This difference was not statistically significant.

Table 1: Personal, epidemiologic characteristics and medical history of CLD patients with and without diabetes (Alexandria, 2012 and 2013)

\begin{tabular}{|c|c|c|c|}
\hline \multirow{3}{*}{$\begin{array}{l}\text { Personal, epidemiologic characteristics and medical } \\
\text { history }\end{array}$} & \multicolumn{2}{|c|}{ Fasting blood glucose level } & \multirow{3}{*}{$\mathbf{X}^{2}$} \\
\hline & $\begin{array}{l}\text { Normal } \\
(\mathbf{n}=\mathbf{1 7 5})\end{array}$ & $\begin{array}{l}\text { IFG and diabetes } \\
(\mathbf{n}=\mathbf{8 9})\end{array}$ & \\
\hline & No. $(\%)$ & No. $(\%)$ & \\
\hline \multicolumn{4}{|l|}{ 1- Age (in years) } \\
\hline$<40$ & $8(72.7)$ & $3(27.3)$ & \multirow{6}{*}{$\begin{array}{c}6.64 \\
p=0.156\end{array}$} \\
\hline $40-$ & 65 (70.7) & $27(29.3)$ & \\
\hline $50-$ & $49(62.8)$ & $29(37.2)$ & \\
\hline $60-$ & $34(56.7)$ & $26(43.3)$ & \\
\hline$\geq 70$ & $19(82.6)$ & $4(17.4)$ & \\
\hline Mean \pm SD & $54.22 \pm 10.33$ & $54.08 \pm 9.94$ & \\
\hline \multicolumn{4}{|l|}{ 2-Sex } \\
\hline Males & $106(65.8)$ & $55(34.2)$ & \multirow{3}{*}{$\begin{array}{c}0.037 \\
\mathrm{p}=0.847\end{array}$} \\
\hline Females & $69(67.0)$ & $34(33.0)$ & \\
\hline \multicolumn{3}{|l|}{ 3- BMI $(n=78)^{a}$} & \\
\hline Normal & $11(100.0)$ & $0(0.0)$ & \multirow{4}{*}{$\begin{array}{c}14.99^{*} \\
\mathrm{p}=0.001\end{array}$} \\
\hline Overweight & $36(75.0)$ & $12(25.0)$ & \\
\hline Obese & $7(36.8)$ & $12(63.2)$ & \\
\hline Mean \pm SD & $27.41 \pm 2.7$ & $30.09 \pm 3.19$ & \\
\hline \multicolumn{4}{|l|}{ 4- History of hypertension } \\
\hline Yes & $39(43.3)$ & $51(56.7)$ & \multirow{2}{*}{$\begin{array}{l}32.197 * \\
\mathrm{p}=0.000\end{array}$} \\
\hline No & $136(78.2)$ & $38(21.8)$ & \\
\hline \multicolumn{4}{|l|}{ 5- Family history of diabetes } \\
\hline Yes & $47(46.5)$ & $54(53.5)$ & \multirow{2}{*}{$\begin{array}{r}28.56^{*} \\
\mathrm{p}=0.000\end{array}$} \\
\hline No & $128(78.5)$ & $35(21.5)$ & \\
\hline \multicolumn{4}{|l|}{ 6- Smoking } \\
\hline Yes & $78(65.0)$ & $42(35.0)$ & \multirow{2}{*}{$\begin{array}{c}0.163 \\
\mathrm{p}=0.69\end{array}$} \\
\hline No & $97(67.4)$ & 47 (32.6) & \\
\hline \multicolumn{4}{|l|}{ 7-Interferon treatment } \\
\hline Yes & $16(59.3)$ & $11(40.4)$ & 0.67 \\
\hline No & $159(67.1)$ & $78(32.9)$ & $\mathrm{p}=0.42$ \\
\hline
\end{tabular}

Figure 1 illustrates that the prevalence of glucose abnormalities among HCV positive patients was higher than that among patients with other CLD (39.2\% versus $21.7 \%$ respectively). This difference was statistically significant $\left(\mathrm{X}^{2}=7.834, \mathrm{p}=0.005\right)$. As shown in table 2, higher percentages of abnormal fasting blood glucose levels were noticed among CLD patients with high GGT levels compared to those with normal levels. 


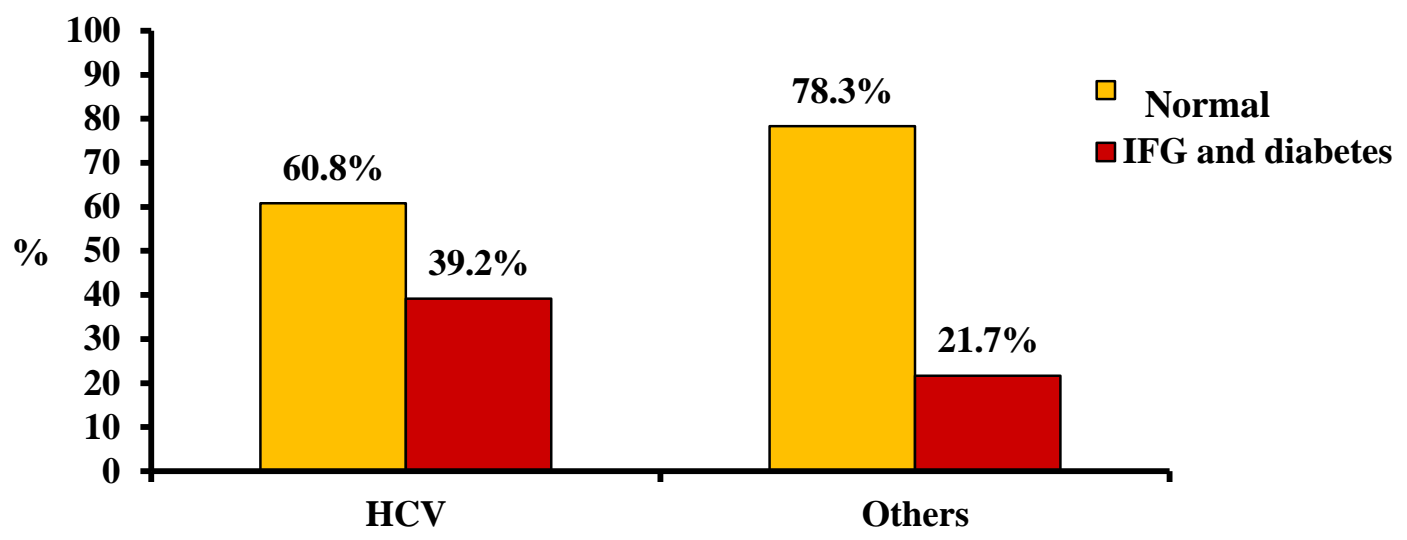

Figure 1. Glucose abnormalities among CLD patients according to the etiology of liver disease (Alexandria, 2012 and 2013)

This difference was statistically significant $\left(X^{2}=14.56\right.$, $\mathrm{p}=0.000$ ). The table also shows that the association between serum albumin level, prothrombin time and activity, serum bilirubin level and fasting glucose levels was not statistically significant. It is also shown in the table that the prevalence of glucose abnormalities was higher among CLD patients with high ALT and AST levels. This difference was not statistically significant. Much higher percentages of CLD patients who had fatty liver changes had fasting glucose abnormalities, with a statistically significant difference $\left(\mathrm{X}^{2}=58.775, \mathrm{p}=0.000\right)$. Nearly equal proportion of CLD patients with and without cirrhosis/fibrosis had glucose abnormalities. This difference was not statistically significant. The highest prevalence of glucose abnormalities was noticed among patients with Child class C. This difference was not statistically significant.

Table 2: Liver profile and imaging of CLD patients with and without diabetes (Alexandria, 2012 and 2013)

\begin{tabular}{|c|c|c|c|}
\hline \multirow{3}{*}{ Liver profile and imaging } & \multicolumn{2}{|c|}{ Fasting blood glucose level } & \multirow{3}{*}{ Test of significance } \\
\hline & $\begin{array}{l}\text { Normal } \\
(n=175)\end{array}$ & $\begin{array}{l}\text { IFG and diabetes } \\
(n=89)\end{array}$ & \\
\hline & No. $(\%)$ & No. $(\%)$ & \\
\hline \multicolumn{4}{|l|}{ 1- GGT level } \\
\hline Normal (9-45 U/L) & $112(76.2)$ & $35(23.8)$ & \multirow{3}{*}{$\begin{aligned} X^{2} & =14.56^{*} \\
p & =0.000\end{aligned}$} \\
\hline$>45 \mathrm{U} / \mathrm{L}$ & $63(53.8)$ & $54(46.2)$ & \\
\hline Mean \pm SD & $50.81 \pm 42.31$ & $75.38 \pm 66.54$ & \\
\hline \multicolumn{4}{|l|}{ 2- Serum albumin } \\
\hline Normal (3.5-5.3 gm/dl) & $12(60.0)$ & $8(40.0)$ & \multirow{3}{*}{$\begin{array}{c}\mathrm{X}^{2}=0.383 \\
\mathrm{p}=0.536\end{array}$} \\
\hline$<3.5 \mathrm{gm} / \mathrm{dl}$ & $163(66.8)$ & $81(33.2)$ & \\
\hline Mean \pm SD & $2.62 \pm 0.52$ & $2.68 \pm 0.52$ & \\
\hline \multicolumn{4}{|l|}{ 3- Prothrombin time } \\
\hline Normal (11-13.5 seconds) & $30(60.0)$ & $20(40.0)$ & \multirow{3}{*}{$\begin{array}{c}X^{2}=1.091 \\
p=0.296\end{array}$} \\
\hline$>13.5$ seconds & $145(67.8)$ & $69(32.2)$ & \\
\hline Mean \pm SD & $17.29 \pm 4.64$ & $15.95 \pm 3.24$ & \\
\hline \multicolumn{4}{|l|}{ 4- Prothrombin activity } \\
\hline Normal (70-100\%) & $19(61.3)$ & $12(38.7)$ & \multirow{3}{*}{$\begin{array}{c}X^{2}=0.393 \\
p=0.531\end{array}$} \\
\hline$<70 \%$ & $156(67.0)$ & $77(33.0)$ & \\
\hline Mean \pm SD & $51.57 \pm 14.25$ & $55.68 \pm 14.59$ & \\
\hline \multicolumn{4}{|l|}{ 5- Serum bilirubin } \\
\hline Normal $(0.3-1.5 \mathrm{mg} / \mathrm{dl})$ & $28(57.1)$ & $21(42.9)$ & \multirow{3}{*}{$\begin{array}{c}\mathrm{X}^{2}=2.252 \\
\mathrm{p}=0.133\end{array}$} \\
\hline$>1.5 \mathrm{mg} / \mathrm{dl}$ & $147(68.4)$ & $68(31.6)$ & \\
\hline Mean \pm SD & $3.95 \pm 3.83$ & $3.52 \pm 4.19$ & \\
\hline \multicolumn{4}{|l|}{ 6- ALT level } \\
\hline Normal (10-40 U/L) & $94(70.1)$ & $40(29.9)$ & \multirow{3}{*}{$\begin{array}{c}\mathrm{X}^{2}=1.816 \\
\mathrm{p}=0.178\end{array}$} \\
\hline$>40 \mathrm{U} / \mathrm{L}$ & $81(62.3)$ & $49(37.7)$ & \\
\hline Mean \pm SD & $44.89 \pm 25.55$ & $48.71 \pm 27.20$ & \\
\hline \multicolumn{4}{|l|}{ 7- AST level } \\
\hline Normal (10-34 U/L) & $28(73.7)$ & $10(26.3)$ & \multirow{3}{*}{$\begin{array}{c}X^{2}=1.087 \\
p=0.297\end{array}$} \\
\hline$>34 \mathrm{U} / \mathrm{L}$ & $147(65.0)$ & $79(35.0)$ & \\
\hline Mean \pm SD & $61.95 \pm 41.02$ & $70.56 \pm 54.61$ & \\
\hline \multicolumn{4}{|l|}{ 8- Fatty liver changes } \\
\hline Yes & $78(48.4)$ & $83(51.6)$ & \multirow{2}{*}{$\begin{aligned} X^{2} & =58.775^{*} \\
p & =0.000\end{aligned}$} \\
\hline No & 97 (94.2) & $6(5.8)$ & \\
\hline
\end{tabular}




\begin{tabular}{|c|c|c|c|}
\hline 9- Liver cirrhosis/fibrosis & & & Fisher Exact \\
\hline Yes & $167(66.5)$ & $84(33.5)$ & test $=0.138$ \\
\hline No & $8(61.5)$ & $5(38.5)$ & $p=0.767$ \\
\hline \multicolumn{4}{|l|}{ 4- Child class $(n=251)^{a}$} \\
\hline A & $4(66.7)$ & $2(33.3)$ & \multirow{4}{*}{$\begin{array}{c}\mathrm{MCP}=3.03 \\
\mathrm{p}=0.21\end{array}$} \\
\hline $\mathrm{B}$ & $51(75.0)$ & $17(25.0)$ & \\
\hline $\mathrm{C}$ & $112(63.3)$ & $65(36.7)$ & \\
\hline Mean \pm SD & $10.07 \pm 1.83$ & $10.92 \pm 1.76$ & \\
\hline
\end{tabular}

It is noticed from table 3 that the association between hemoglobin level, platelet count and fasting glucose level was not statistically significant, while the association between WBC count and fasting glucose level was statistically significant $(\mathrm{MCP}=9.04, \mathrm{p}=0.01)$. It is clear from the table that the prevalence of abnormal fasting glucose levels among CLD patients increased with the increase in the triglycerides and total cholesterol levels. These differences were statistically significant $\left(X^{2}=49.18\right.$ and 73.51, $p=0.000$, respectively). Table 4 shows the logistic regression analysis of the factors associated with abnormal fasting blood glucose levels among patients with CLD as the dependent variable. Three independent factors

Table 3: Blood picture and lipid profile of chronic liver disease patients with and without diabetes (Alexandria, 2012 and 2013)

\begin{tabular}{|c|c|c|c|}
\hline \multirow{3}{*}{ Blood picture and lipid profile } & \multicolumn{2}{|c|}{ Fasting blood glucose level } & \multirow{3}{*}{ Test of significance } \\
\hline & \multirow{2}{*}{$\begin{array}{l}\text { Normal } \\
(n=175)\end{array}$} & \multirow{2}{*}{$\begin{array}{c}\text { IFG and diabetes } \\
(n=89)\end{array}$} & \\
\hline & & & \\
\hline \multicolumn{4}{|l|}{ 1- Hemoglobin level } \\
\hline Normal & $2(33.3)$ & $4(66.7)$ & \multirow{3}{*}{$\begin{array}{c}\text { Fisher's Exact } \\
\text { test }=2.984 \\
\mathrm{p}=0.184\end{array}$} \\
\hline Anemic & $173(67.1)$ & $85(32.9)$ & \\
\hline Mean \pm SD & $9.1 \pm 1.61$ & $9.76 \pm 1.86$ & \\
\hline \multicolumn{4}{|l|}{ 2- WBC count (in thousands $/ \mathrm{mm}^{3}$ ) } \\
\hline Normal & $86(63.2)$ & $50(36.8)$ & \multirow{4}{*}{$\begin{array}{c}\mathrm{MCP}=9.04^{*} \\
\mathrm{p}=0.01\end{array}$} \\
\hline$<4500$ & $88(72.1)$ & $34(27.9)$ & \\
\hline$>10000$ & $1(16.7)$ & $5(83.3)$ & \\
\hline Mean \pm SD & $4.87 \pm 2.12$ & $5.84 \pm 2.98$ & \\
\hline \multicolumn{4}{|c|}{ 3- Platelet count (in thousands $/ \mathrm{mm}^{3}$ ) } \\
\hline Normal (150-400) & $22(61.1)$ & $14(38.9)$ & \multirow{3}{*}{$\begin{array}{l}\mathrm{X}^{2}=0.5 \\
\mathrm{p}=0.48\end{array}$} \\
\hline$<150$ & $153(67.1)$ & $75(32.9)$ & \\
\hline Mean \pm SD & $86.37 \pm 48.31$ & $99.74 \pm 57.93$ & \\
\hline \multicolumn{4}{|l|}{ 4- Triglycerides (mg/dl) } \\
\hline Normal $(<150)$ & $104(83.9)$ & $20(16.1)$ & \multirow{5}{*}{$\begin{array}{c}\mathrm{X}^{2}=49.18^{*} \\
\mathrm{p}=0.000\end{array}$} \\
\hline Borderline high $(150-<200)$ & $58(62.4)$ & $35(37.6)$ & \\
\hline High $(200-<500)$ & $13(27.7)$ & $34(72.3)$ & \\
\hline Very high $(\geq 500)$ & $0(0.0)$ & $0(0.0)$ & \\
\hline Mean \pm SD & $130.18 \pm 51.35$ & $184.21 \pm 55.67$ & \\
\hline \multicolumn{4}{|l|}{ 5- Total cholesterol (mg/dl) } \\
\hline Normal $(<200)$ & $144(84.2)$ & $27(15.8)$ & \multirow{4}{*}{$\begin{array}{c}\mathrm{X}^{2}=73.51 * \\
\mathrm{p}=0.000\end{array}$} \\
\hline Borderline high $(200-<240)$ & $26(39.4)$ & $40(60.6)$ & \\
\hline $\operatorname{High}(\geq 240)$ & $5(18.5)$ & $22(81.5)$ & \\
\hline Mean \pm SD & $145.78 \pm 52.92$ & $212.31 \pm 50.19$ & \\
\hline
\end{tabular}

* Significant $(\mathrm{p}<0.05)$

IFG, Impaired fasting glucose; SD, standard deviation; WBC, White Blood Cell; MCP, Monte Carlo Probability test

were found to be significantly affecting the prevalence of glucose abnormalities. The first factor was the etiology of liver disease. CLD patients with abnormal fasting blood glucose levels were 2.74 times more likely to have $\mathrm{HCV}$ infection compared to CLD patients with normal fasting blood glucose levels $(\mathrm{OR}=2.74$, 95\% $\mathrm{CI}=1.23-6.14)$. The second factor was the presence of fatty liver. CLD patients with abnormal fasting blood glucose levels were 3.82 times more likely to have fatty liver compared to CLD patients with normal fasting blood glucose levels $(\mathrm{OR}=3.82,95 \%$ $\mathrm{CI}=1.38-10.56)$. The third factor was the total cholesterol level $(\mathrm{OR}=1.02,95 \% \mathrm{CI}=1.01-1.03)$. The model correctly classified $83.8 \%$ of cases. 
Table 4: Logistic regression analysis of factors associated with glucose abnormalities among CLD patients (Alexandria 2012 and 2013)

\begin{tabular}{lcccc}
\hline Independent variables & $\begin{array}{c}\text { Coefficient } \\
\text { B }\end{array}$ & $\boldsymbol{p}$. value & Odds ratio & $\begin{array}{c}\mathbf{9 5 \%} \\
\text { Confidence Interval }\end{array}$ \\
\hline Etiology of liver disease & 1.01 & 0.014 & 2.74 & $1.23-6.14$ \\
Fatty liver changes & 1.34 & 0.010 & 3.82 & $1.38-10.56$ \\
Cholesterol level & 0.02 & 0.001 & 1.02 & $1.01-1.03$ \\
Constant & -8.38 & & & \\
\hline
\end{tabular}

Sensitivity of the model was $83.8 \%$

\section{DISCUSSION}

The close relationship between DM and chronic HCV infection had been reported in several previous studies in the eighties and nineties. ${ }^{(5-7,15-19)}$ In the present study, the prevalence of abnormal fasting glucose levels was 39.2\% among HCV positive patients and $21.7 \%$ among other CLD patients. These findings were in accordance with other studies. In Iran (2004), abnormal fasting glucose levels were diagnosed in $32.9 \%$ of CLD patients. ${ }^{(20)}$ In another study conducted in China (2003), 34.6\% of chronic hepatitis C patients had glucose intolerance. ${ }^{(21)}$ Diabetes mellitus was also present in $13 \%$ of chronic viral hepatitis patients as reported in a Greek study conducted between 1998 and $2006 .{ }^{(22)}$ Lower prevalence of DM (27.5\%) among chronic HCV patients was reported in Japan (2004). ${ }^{(23)}$

Although this close relationship between DM and chronic $\mathrm{HCV}$ infection has been noted, different risk factors were reported in various studies. Age and family history of DM are definite risk factors for type $2 \mathrm{DM}$ in the normal population, and it was expected also to be associated with DM in CLD.

However, univariate analysis of the current data showed that age was not significantly associated with abnormal blood glucose levels among CLD patients, in contrast to other studies. On the other hand, positive family history of DM, elevated BMI, higher GGT and increased triglyceride concentrations were among the factors significantly associated with abnormal blood glucose level in univariate analysis of our data, which was in agreement with these studies. ${ }^{(20,21,24)}$

Logistic regression analysis in the current work showed that the etiology of liver disease, the presence of fatty liver changes and cholesterol level were the only independent variables significantly associated with glucose abnormalities among patients with CLD. Age and family history of DM were among the factors significantly associated with abnormal glucose levels among CLD patients in other studies. ${ }^{(20,21)}$ Other reported risk factors included chronic hepatitis and cirrhosis (Iran, 2004), ${ }^{(20)}$ and obesity and previous interferon treatment (China, 2003). ${ }^{(21)}$

\section{CONCLUSION AND RECOMMENDATIONS}

The present study indicates a high prevalence of DM in patients with CLD in Alexandria. Chronic HCV infection, presence of fatty liver and higher cholesterol levels were the factors significantly associated with abnormal glucose levels among CLD patients. It is therefore imperative that patients with CLD especially chronic hepatitis C patients be screened for glucose intolerance periodically.

\section{CONFLICT OF INTEREST}

All authors declare no conflict of interest

\section{REFERENCES}

1. Johns Hopkins Medicine [Internet]. Baltimore: The Organization; [cited 2013 Sep 15]. The Johns Hopkins University, The Johns Hopkins Hospital, and Johns Hopkins Health System; [about 6 screens]. Available from: http://www.hopkinsmedicine.org/healthlibrary/conditions/liver_ biliary_and_pancreatic_disorders/chronic_liver_diseasecirrhosis 85,P00662/

2. Riley TR, Ahsan MB. Preventive Strategies in Chronic Liver Disease: Part I. Alcohol, Vaccines, Toxic Medications and Supplements, Diet and Exercise. Am Fam Physician. 2001;64(9):1555-61.

3. Strickland GT. Liver disease in Egypt: hepatitis C superseded schistosomiasis as a result of iatrogenic and biological factors. Hepatology. 2006;43(5): 915-22.

4. Strickland GT, Elhefni H, Salman T, Waked I, Abdel Hamid M, Mikhail N, et al. The role of hepatitis $\mathrm{C}$ infection in chronic liver disease in Egypt. The American Journal of Tropical Medicine and Hygiene. 2002;67(4):436-42.

5. Allison ME, Wreghitt T, Palmer CR, Alexander GJ. Evidence for a link between hepatitis $\mathrm{C}$ virus infection and diabetes mellitus in a cirrhotic population. Hepatol. 1994;21:1135-9.

6. Mason AL, Lau JK, Hoang N, Qian K, Alexander GJ, Xu L, et al. Association of diabetes mellitus and chronic hepatitis $\mathrm{C}$ virus infection. Hepatology. 1999;29:328-33.

7. Simo R, Hernandez C, Genesca J, Jardi R, Mesa J. High prevalence of hepatitis $\mathrm{C}$ virus infection among diabetic patients. Diabetes care. 1996;19:998-1000.

8. Fraser GM, HarmanI, Meller N, Niv Y, Porath A. Diabetes Mellitus is associated with chronic hepatitis $\mathrm{C}$ but not chronic hepatitis B infection. Isr J Med Sci. 1996;32(7):568-70.

9. García-Compean D, Jaquez-Quintana JO, Maldonado-Garza H. Hepatogenous diabetes. Current views of an ancient problem. Ann Hepatol. 2009 ; 8 (1):13-20.

10. Holstein A, Plaschke A, Egberts EH. Clinical implication of hepatogenous diabetes in liver cirrhosis. J Gastroenterol Hepatol. 2002;17:677-81.

11. Pincus MR, Abraham Jr NZ. Interpreting laboratory results. In: McPherson RA, Pincus MR, eds. Henry's Clinical Diagnosis and Management by Laboratory Methods. Philadelphia, Pa: Saunders Elsevier; 2011.p. 91-108. 
12. Sherlock S, Dooley J. Hepatic cirrhosis. In: Sherlock S, Dooley $\mathrm{J}$. Diseases of the liver and biliary system. London: Blackwell Science; 2002. p. 365-80.

13. Chobanian AV, Bakris GL, Black HR, Cushman WC, Green LA, Izzo Jr. JL, et al. Seventh report of the Joint National Committee on Prevention, Detection, Evaluation, and Treatment of High Blood Pressure.

Hypertension. 2003;42(6):1206-52.

14. World Health Organization. Physical status: the use and interpretation of anthropometry. Report of a WHO expert committee. Geneva: WHO; 1995.Technical Report Series No.: 854.

15. Kingston ME, Ali MA, Atiyeh M, Donnelly RJ. Diabetes mellitus in chronic active hepatitis and cirrhosis. Gastroenterology. 1984;87:688-94.

16. Ozyilkan E, Erbas T, Simsek H, Telatar F, Kayhan B, Telatar H. Increased prevalence of hepatitis $\mathrm{C}$ virus antibodies in patients with diabetes mellitus. J Intern Med. 1994;235:283-4.

17. Knobler H, Stagnaro-Green A, Wallenstein S, Schwartz M, Roman SH. Higher incidence of diabetes in liver transplant recipients with hepatitis C. J Clin Gastroenterol. 1998;26:30-3.

18. Caronia S, Taylor K, Pagliaro L, Carr C, Palazzo U, Petrik J, et al. Further evidence for an association between non-insulin- dependent diabetes mellitus and chronic hepatitis $\mathrm{C}$ virus infection. Hepatology. 1999;30:1059-63.

19. Bigam DL, Pennington JJ, Carpentier A, Wanless IR, Hemming AW, Croxford R, et al. Hepatitis C-related cirrhosis: a predictor of diabetes after liver transplantation. Hepatology. 2000;32:8790.

20. Alavian SM, Hajarizadeh B, Nematizadeh F, Larijani B. Prevalence and determinants of diabetes mellitus among Iranian patients with chronic liver disease. BMC Endocrine Disorders. 2004;4:4.

21. Chen LK, Hwang SJ, Tsai ST, Luo JC, Lee SD, Chang FY. Glucose intolerance in Chinese patients with chronic hepatitis C. World J Gastroenterol. 2003;9(3):505-8.

22. Papatheodoridis GV, Chrysanthos N, Savvas S, Sevastianos V, Kafiri G, Petraki K, et al. Diabetes mellitus in chronic hepatitis $\mathrm{B}$ and C: Prevalence and potential association with the extent of liver fibrosis. J Viral Hepat. 2006;13(5):303-10.

23. Narita R, Abe S, Kihara Y, Akiyama T, Tabaru A, Otsuki M. Insulin resistance and insulin secretion in chronic hepatitis $\mathrm{C}$ virus infection. J Hepatol. 2004;41(1):132-8.

24. Wang CS, Wang ST, Yao WJ, Chang TT, Chou P. Community based study of hepatitis $\mathrm{C}$ virus infection and type 2 diabetes: An association affected by age and hepatitis severity status. Am J Epidemiol. 2003;158: 1154-60. 